\title{
Quantitative Comparison of Direct Current Shunt and Series Motors Speed Control Methods
}

\author{
P. I. Obi, O. Oputa, C. A. Okeke, G. C. Diyoke and I. K. Onwuka
}

\begin{abstract}
The desired speed of DC motors in most cases is a function of the intending usage, hence, the speed is continually regulated/controlled to suit different usage. Three basic methods are employed in the speed control; the quantitative comparison of these methods was investigated in this paper. For shunt and series motors delivering $11.07 \mathrm{Hp}$ and $13.94 \mathrm{Hp}$ respectively (at rated speed), the efficiencies were $84.43 \%$ and $90.22 \%$ with running cost of $\$ 246.00$ and $\$ 276.00$ respectively. Increasing the shunt motor speed by reducing armature resistance (armature control) reduces the running cost but increases the efficiency from its original values to $\$ 238.70$ and $82.89 \%$ respectively at 0.6 of the rated armature resistance; decreasing the speed of the motor by this means decreases efficiency and increases running cost. However, increasing the motor speed by decreasing the armature resistance for series dc motors decreases efficiency and also increases running cost, with 0.6 of rated armature resistance used, the efficiency dropped to $83.15 \%$ while running cost went up to $\$ 299.47$. But decreasing the series motor speed increases efficiency and reduces running cost.
\end{abstract}

Index Terms-Comparison; Quantitative; Speed Control Methods.

\section{INTRODUCTION}

DC motors are extensively used in manufacturing industries, electric power generation and generating plants, laboratories and other sectors in driving and lifting loads from one place to another at different speeds. The control of the speed of these motors is of great concern to the users of these machines as the speed varies with its usage. A lot of research has been done in finding different ways of controlling the speed of these dc motors. The speed of the dc motor is given by

$$
N=\frac{V-I_{a} R_{a}}{Z \emptyset}\left(\frac{A}{P}\right)
$$

From (1), the speed of a dc motor can basically be controlled by three methods of:

1. Altering the flux per pole of the motor.

2. Altering the supply voltage to the motor.

3. Altering the armature resistance.

\section{A. Speed Control by Flux Variation}

From (1), the motor speed N, is in inverse proportionality with the flux per pole $\varnothing$; hence, the motor speed can be control by varying $\varnothing$, by increasing or decreasing $\varnothing$, the motor speed will decrease or increase respectively. The rate of flux changes when the shunt current is varied using a

Published on July 4, 2018.

Authors are with the Department of Electrical/Electronic Engineering, Michael Okpara University of Agriculture, Umuahia, Abia State, Nigeria (e-mail: connectositao@gmail.com). shunt field rheostat. Since the shunt current is relatively small, the shunt field rheostat has to carry only a small current which results in low shunt copper loss (in shunt dc motors), such rheostat is small in size. This method is therefore very efficient. However, the reduction of the flux per pole in order to increase the motor speed should be done with great care as over weakening of the flux per pole adversely affect the communication; therefore, there is a limit to which this method can be used; in most cases, it is a maximum to minimum speed ratio of 6:1 [1]. The method of changing the shunt resistance can be either of Field Diverter Method, Tapped Field Control and Paralleling Field coils Method especially in series dc motors [2].

\section{Speed Control by Armature Resistance Variation}

The speed is negatively proportional to the armature resistance. In most theoretical cases, this method is very suitable when the desire speed is below the no-load speed. Increasing the resistance of the armature decreases the induced back e.m.f thereby reducing the speed of the motor; this is illustrated in Fig. 1. Like in the case of speed control by altering the shunt resistance, the altering of the armature resistance can also be achieved either by Field Diverter Method, Tapped Field Control and Paralleling Field coils Method especially in series dc motors [2]. However, for rapid changing loads, this method can be very unsuitable when using the tapped field resistance changing method, the field diverter resistance changing method produces fair result.

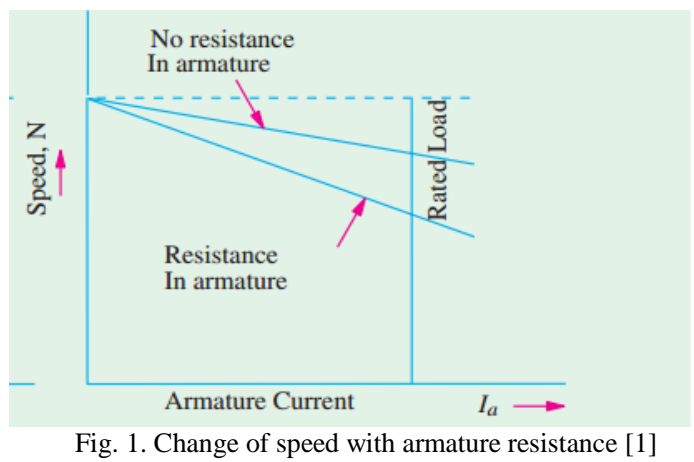

\section{B. Speed Control by Supply Voltage Variation}

Still referring to (1), the supply voltage can also be used in controlling the speed of the motor. This can be done by supplying the armature with varying supply voltage while keeping the shunt filed voltage fixed. For higher speed control ratios, the Ward-Leonard may be used [1].

A combination of the armature and field control methods can be also be archived by using two rheostats. The field rheostat provides above normal speed control and armature 
rheostat provides wide range of below normal speed. The main problem of this method is bulky rheostat is required across the armature so a large amount of power is wasted in the controlling resistance and poor speed regulation results for the lower speed [3].

In recent times, modern methods have been used in the speed control of these motors. The controllers are extremely popular in speed control mechanism because they can usually provide good closed-loop response characteristics, they can be tuned using relatively simple design rules, and are easy to construct using either analog or digital components. The dc motor whose speed is to be controlled using the PID controller in the Fig. 2 is the plant; the controller regulates the motors speed by adjusting one or more of either the supply voltage to the motor, the motor's armature or shunt resistance [4].

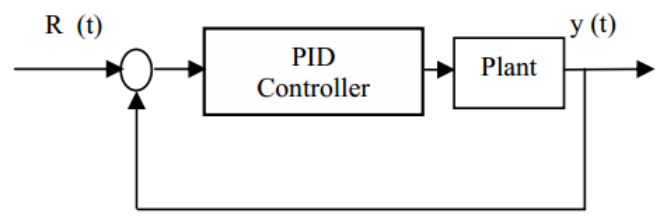

Fig. 2. Feedback system architect of PID controller

Electronic devices/components have also been used in the control of these machines, where chopper circuits are used to reduce armature voltage (voltage control), or shunt current are either amplified or reduced by circuits (flux control); control blocks and MATLAB/Simulink are applied in the analysis of such control systems [5] -[9].

Microcontrollers are rapidly being used for speed control of DC motor; here, the microcontroller is fed by a DC chopper driven by a high frequency pulse width modulator (PWM) signal. Controlling the PWM duty cycle is equivalent to controlling the motor terminal voltage, which in turn adjust directly the motor speed [10].

Having considered the different speed control methods, this paper shall be concerned with drawing a quantitative comparison between the methods basic methods of speed control (as other modern methods revolve around the basic method). The quantitative comparison shall be in terms of the motor efficiency associated with the methods and the cost associated with running the motor when the different methods are used. In the analysis, the output of the machine is assumed to be constant.

\section{COMPARISON IN TERMS OF EFFICIENCY IN SHUNT MOTORS}

\section{A. Controlling speed from the flux per pole}

If the output load and source voltage are constant throughout, then the supply current $I_{L}$ will be constant at all times. The power lost in the shunt $L_{s h}$ is

$L_{s h}=I_{s h}^{2} R_{s h}$ or $L_{s h}=\frac{V^{2}}{R_{s h}}$

The armature copper loss $L_{a m}$ is

$L_{a m}=I_{a}^{2} R_{a}=\left(I_{L}-\frac{V}{R_{s h}}\right)^{2} R_{a}$
If the sum of the windage loss, eddy current and all other constant losses is $L_{c}$, then the total losses $L_{T}$ is

$L_{T}=\left(I_{L}^{2}-\frac{2 V I_{L}}{R_{s h}}+\frac{V^{2}}{R_{s h}^{2}}\right) R_{a}+\frac{V^{2}}{R_{s h}}+L_{c}$

When $R_{s h}$ is altered by an amount $x$ the resulting value of the shunt resistance is $x R_{s h}$, the shunt and armature losses are respectively

$$
\begin{aligned}
& L_{s h x}=\frac{V^{2}}{x R_{s h}}=\frac{1}{x} L_{s h} \\
& L_{a m x}=\left(I_{L}-\frac{V}{x R_{s h}}\right)^{2} R_{a}
\end{aligned}
$$

The total losses $L_{T x}$ is

$$
\begin{aligned}
& L_{T x}=\left(I_{L}^{2}-\frac{2 V I_{L}}{x R_{S h}}+\frac{V^{2}}{x^{2} R_{S h}^{2}}\right) R_{a}+\frac{V^{2}}{x R_{S h}}+L_{c} \\
& \text { If } A=\frac{2 V I_{L}}{R_{S h}} \text { and } B=\frac{V^{2}}{R_{s h}} \text { then (4) and (7) can be written }
\end{aligned}
$$
as in (8) and (9) respectively

$$
\begin{aligned}
& L_{T}=\left(I_{L}^{2}-A+\frac{1}{R_{s h}} B\right) R_{a}+B+L_{c} \\
& L_{T x}=\left(I_{L}^{2}-\frac{1}{x} A+\frac{1}{x^{2} R_{S h}} B\right) R_{a}+\frac{1}{x} B+L_{C}
\end{aligned}
$$

If the output of the machine is to be constant in both cases, then the efficiencies are

$$
\begin{gathered}
\eta=\frac{P_{o / p}}{P_{o / p}+L_{T}} \\
\eta_{x}=\frac{P_{o / p}}{P_{o / p}+L_{T x}}
\end{gathered}
$$

\section{Controlling speed from the armature resistance}

This method tends to vary the back e.m.f by varying the voltage drop at the armature without changing the armature current. If the output load and source voltage are constant throughout, then the shunt current will be constant throughout.

The armature copper and total losses incurred in the system are as given in (3) and (8) respectively.

When the armature resistance is varied by an amount $x$, with constant $I_{L}, I_{a}$ and $I_{s h}$ the total losses is

$L_{T x}=\left[I_{L}^{2}-A+\frac{1}{R_{S h}} B\right] x R_{a}+B+L_{c}$

Again if the output of the machine is to be constant in both cases, then the efficiencies are as given in (10) and (11).

\section{B. Controlling speed from the supply voltage}

With the motor being fed with the rated voltage, the copper and total losses are as given in (3) and (4). When the supply voltage is altered by $x \%$ of the rated voltage with the system resistance (and load) unaltered, the copper and total losses are respectively 
$L_{a x}=\left[x I_{L}-\frac{x V}{R_{s h}}\right]^{2} R_{a}$

$L_{T x}=\left[I_{L}^{2}-\frac{2 V I_{L}}{R_{s h}}+\frac{V^{2}}{R_{S h}^{2}}\right] x^{2} R_{a}+\frac{x^{2} V^{2}}{R_{s h}}+L_{c}$

or

$L_{T x}=\left[I_{L}^{2}-A+\frac{1}{R_{S h}} B\right] x^{2} R_{a}+x^{2} B+L_{c}$

Again the efficiencies are as given in (10) and (11).

\section{COMPARISON IN TERMS OF EFFICIENCY IN SERIES MOTORS}

\section{A. Controlling speed from the flux per pole and armature resistance}

The speed control of dc motors from the armature resistance and the field resistances in series dc motors have similar effect as the armature and field resistances are in series with each other and the supply. In this system, the armature, series and source or line current are the same, i.e $I_{L}=I_{a}=I_{s}$

The total losses in the system is given as

$$
\begin{aligned}
& L_{T}=I_{L}^{2} R_{a}+I_{L}^{2} R_{s}+L_{c} \\
& L_{T}=I_{L}^{2}\left(R_{a}+R_{s}\right)+L_{c}
\end{aligned}
$$

When the armature and field resistances are varied by an amount $x \%$ of the original value without altering the supply voltage for the armature and flux control methods respectively, since we are taking the armature and field resistance as a single unit (i.e $R_{e f f}=R_{a}+R_{s}$ ), we can represent the change in any of $R_{a}$ or $R_{s}$ by an amount $x \%$ as $x R_{e f f}$ and the resulting line current $I_{L x}$ will be $\frac{1}{x} I_{L}$.

$$
L_{T x}=\frac{1}{x^{2}} I_{L}^{2}\left(R_{a}+R_{s}\right)+L_{c}
$$

The respective efficiencies can then be calculated as given in (10) and (11).

\section{B. Controlling speed from the supply voltage}

For a series field dc motor fed with a rated voltage $\mathrm{V}$ and $I_{L}$ flowing in the series circuit, when the voltage is varied by an amount $x \%$ of $\mathrm{V}$ so that it is now being fed with $x V$ without changing and part of the system resistance, the resulting current is $x I_{L}$. Hence, the losses associated with feeding the dc motor with rated voltage and $x \%$ of rated voltage are as given in (17) and (21).

$$
L_{T x}=x^{2} I_{L}^{2}\left(R_{a}+R_{S}\right)+L_{c}
$$

The respective efficiencies can then be calculated as given in (10) and (11).

\section{COMPARING IN TERMS OF COST OF ENERGY}

The cost of energy in running the system is the cost of the sum of power output and power losses for the duration of running the system. In all cases, it will be assumed that the delivered output is the same at all times and the duration of supplying the power is constant for all the cases considered. With the energy rate of sale as $R_{e c}$, the cost of running the systems are respectively

$$
\begin{aligned}
& S_{r c}=\left[L_{T}+P_{o / p}\right] R_{e c} \\
& S_{r c x}=\left[L_{T x}+P_{o / p}\right] R_{e c}
\end{aligned}
$$

\section{MOdEL TESTING/System ANALYSIS}

We shall test the models developed with a $11.066 \mathrm{HP}$ and 13.936HP rated shunt and series motors respectively with parameters given in Table I. The other parameters found in Table I but not on the name plate of the motors where found from experiments performed at the machine laboratory of Electrical/Electronic Engineering, Michael Okpara University of Agriculture, Umudike, Abia State, Nigeria.

TABLE I: PARAMETERS OF SPECIMEN DC MOTOR

\begin{tabular}{clll}
\hline \hline \multicolumn{2}{c}{ Shunt Motor } & \multicolumn{2}{c}{ Series Motor } \\
\hline Rated V & $250.00 \mathrm{~V}$ & Rated $\mathrm{V}$ & $230.00 \mathrm{~V}$ \\
Rated $R_{a}$ & $0.50 \Omega$ & Rated $R_{a}$ & $0.11 \Omega$ \\
Rated $R_{s h}$ & $250.00 \Omega$ & Rated $R_{s}$ & $0.11 \Omega$ \\
Delivered output & $11.066 \mathrm{HP}$ & Delivered output & $13.936 \mathrm{HP}$ \\
$I_{L}$ & $40.00 \mathrm{~A}$ & $I_{L}$ & $50.00 \mathrm{~A}$ \\
$L_{c}$ & $995.50 \mathrm{~W}$ & $L_{c}$ & $575.00 \mathrm{~W}$ \\
\hline \hline
\end{tabular}

With energy sold at $\mathrm{N} 24 / \mathrm{kWhr}$, the total losses and total running cost associated with the system when run normally is given on Table II. We assumed that the motors in all cases ran for one hour

TABLE II: ANALYSIS OF THE MOTOR WHEN RUNNING NORMALLY

\begin{tabular}{cccc}
\hline \multicolumn{2}{c}{ Shunt Motor } & \multicolumn{2}{c}{ Series Motor } \\
\hline$S_{r c}(\Uparrow)$ & 246.00 & $S_{r c}(\$)$ & 276.00 \\
$\eta(\%)$ & 80.43 & $\eta(\%)$ & 90.22 \\
\hline
\end{tabular}

TABLE III: ANALYSIS OF THE MOTOR WHEN SPEED IS CONTROLLED BY VARYING ARMATURE RESISTANCE

\begin{tabular}{cccccc}
\hline \hline \multicolumn{3}{c}{ Shunt Motor } & \multicolumn{3}{c}{ Series Motor } \\
$x=\% R_{a}$ & $\begin{array}{c}S_{r c x} \\
(\mathrm{~N})\end{array}$ & $\begin{array}{c}\eta_{x} \\
(\%)\end{array}$ & $\begin{array}{l}x \\
=\% R_{\text {eff }}\end{array}$ & $\begin{array}{c}S_{r c} \\
(\mathrm{~N})\end{array}$ & $\begin{array}{c}\eta_{x} \\
(\%)\end{array}$ \\
\hline 0.6 & 238.70 & 82.89 & 0.6 & 299.47 & 83.15 \\
0.7 & 240.52 & 82.26 & 0.7 & 289.74 & 85.94 \\
0.8 & 242.35 & 81.64 & 0.8 & 283.43 & 87.85 \\
0.9 & 244.17 & 81.03 & 0.9 & 279.10 & 89.22 \\
1.1 & 247.83 & 79.84 & 1.1 & 273.71 & 90.97 \\
1.2 & 249.65 & 79.25 & 1.2 & 271.97 & 91.56 \\
1.3 & 251.48 & 78.68 & 1.3 & 270.61 & 92.01 \\
1.4 & 253.30 & 78.11 & 1.4 & 269.53 & 92.38 \\
1.5 & 255.13 & 77.55 & 1.5 & 268.67 & 92.68 \\
\hline \hline
\end{tabular}


TABLE IV: ANALYSIS OF THE MOTOR WHEN SPEED IS CONTROLLED BY VARYING FIELD/SHUNT RESISTANCE

\begin{tabular}{cccccc}
\hline \hline \multicolumn{3}{c}{ Shunt Motor } & \multicolumn{3}{c}{ Series Motor } \\
$x$ & $S_{r c x}$ & $\eta_{x}$ & $x=\% R_{\text {eff }}$ & $\begin{array}{c}S_{r c} \\
(\mathrm{~N})\end{array}$ & $\begin{array}{c}\eta_{x} \\
(\%)\end{array}$ \\
\hline 0.6 & 249.38 & 79.34 & 0.6 & 299.47 & 83.15 \\
0.7 & 248.17 & 79.73 & 0.7 & 289.74 & 85.94 \\
0.8 & 247.27 & 80.02 & 0.8 & 283.43 & 87.85 \\
0.9 & 246.56 & 80.25 & 0.9 & 279.10 & 89.22 \\
1.1 & 245.54 & 80.58 & 1.1 & 273.71 & 90.97 \\
1.2 & 245.16 & 80.71 & 1.2 & 271.97 & 91.56 \\
1.3 & 244.83 & 80.81 & 1.3 & 270.61 & 92.01 \\
1.4 & 244.55 & 80.90 & 1.4 & 269.53 & 92.38 \\
1.5 & 244.31 & 80.98 & 1.5 & 268.67 & 92.68 \\
\hline \hline
\end{tabular}

Note that for series dc motor, the fraction taken is that of the effective resistance of the series and armature resistances.

TABLE V: ANALYSIS OF THE MOTOR WHEN SPEED IS CONTROLLED BY VARYING SUPPLY VOLTAGE

\begin{tabular}{|c|c|c|c|c|c|}
\hline \multicolumn{3}{|c|}{ Shunt Motor } & \multicolumn{3}{|c|}{ Series Motor } \\
\hline$x=\% V$ & $\begin{array}{c}S_{r c x} \\
\text { (N) }\end{array}$ & $\begin{array}{c}\eta_{x} \\
(\%)\end{array}$ & $\begin{array}{l}x \\
=\% R_{\text {eff }}\end{array}$ & $\begin{array}{l}S_{r c} \\
(\mathrm{~N})\end{array}$ & $\begin{array}{c}\eta_{x} \\
(\%)\end{array}$ \\
\hline 0.6 & 230.48 & 85.85 & 0.6 & 93.07 & 267.55 \\
\hline 0.7 & 233.63 & 83.39 & 0.7 & 92.47 & 269.27 \\
\hline 0.8 & 237.27 & 81.96 & 0.8 & 91.80 & 271.25 \\
\hline 0.9 & 241.39 & 80.43 & 0.9 & 91.40 & 273.49 \\
\hline 1.1 & 251.09 & 78.80 & 1.1 & 89.32 & 278.77 \\
\hline 1.2 & 256.67 & 77.09 & 1.2 & 88.36 & 281.80 \\
\hline 1.3 & 262.73 & 75.31 & 1.3 & 87.34 & 285.11 \\
\hline
\end{tabular}

Note also that when the speed is controlled by varying the voltage, the range of $0.6-1.3$ was used so as not to put the machine in danger of low and high voltage.

The plot of the values of $\mathrm{x}$ and the efficiencies and running cost for the different modes are given in Fig. $3-5$.

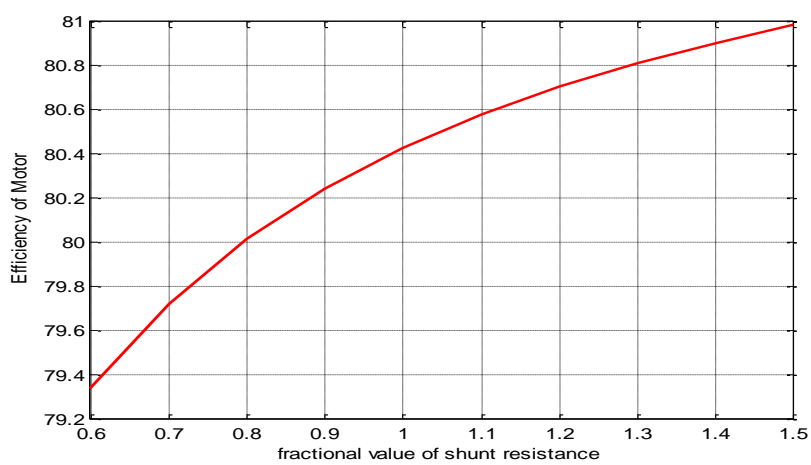

(a)

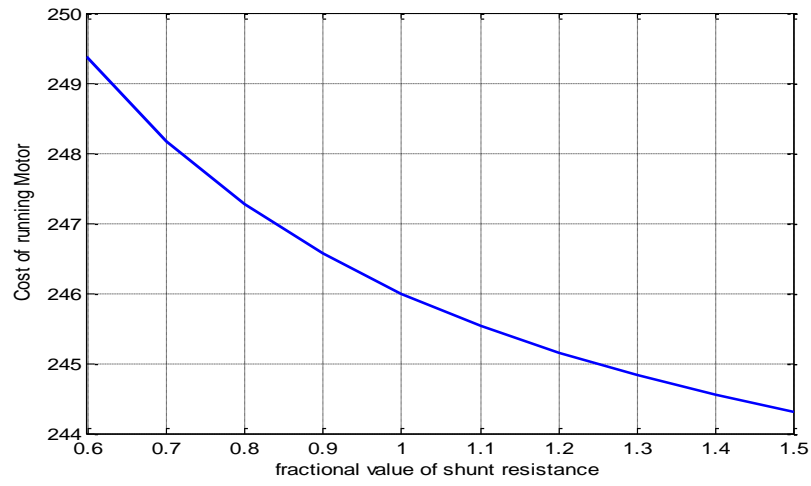

(b)

Fig. 3. Effect of speed control by varying the flux for shunt motors

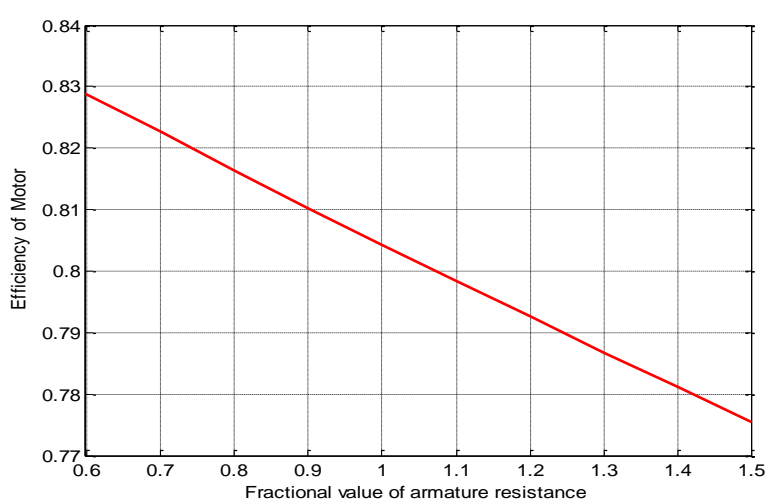

(a)

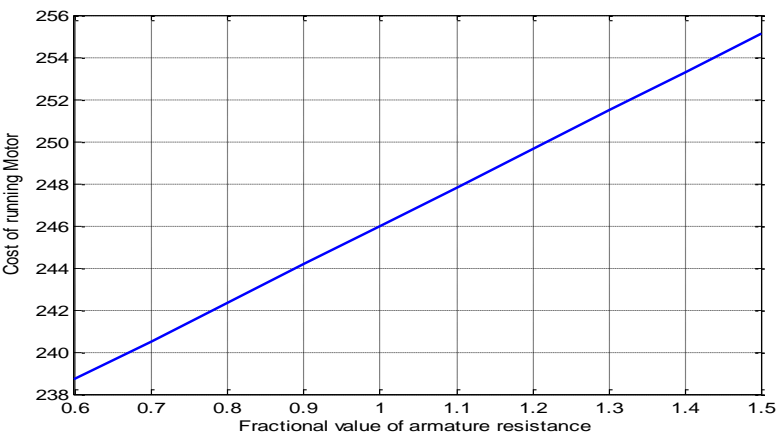

(b)

Fig. 4. Effect of speed control by varying the armature resistance for shunt motors

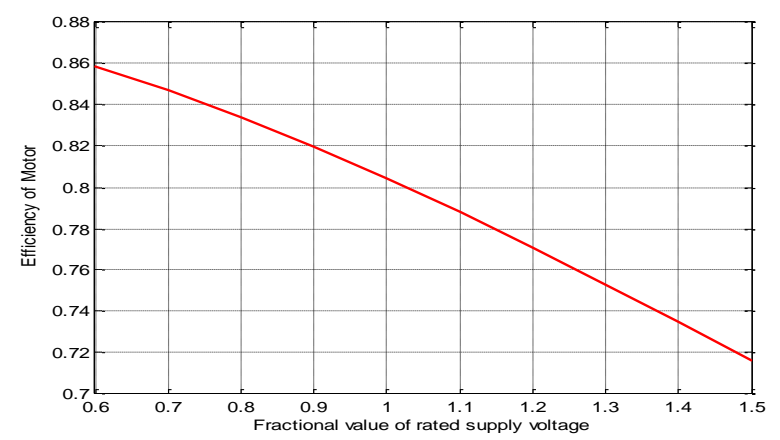

(a)

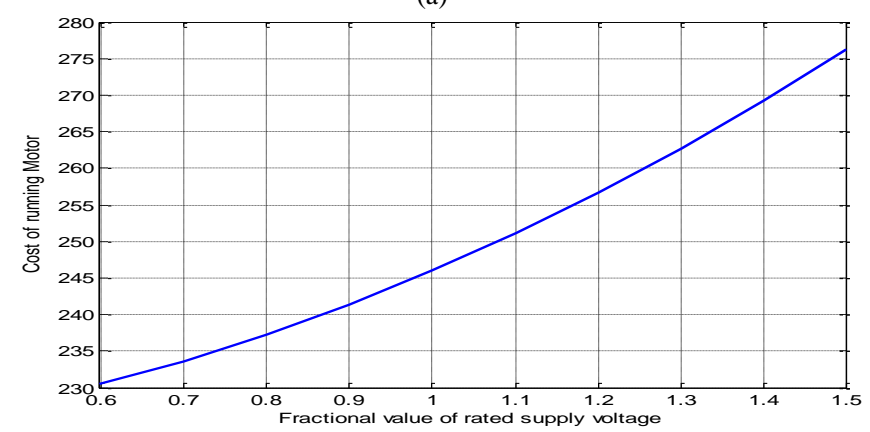

(b)

Fig. 5. Effect of speed control by varying the supply voltage for shunt motors 


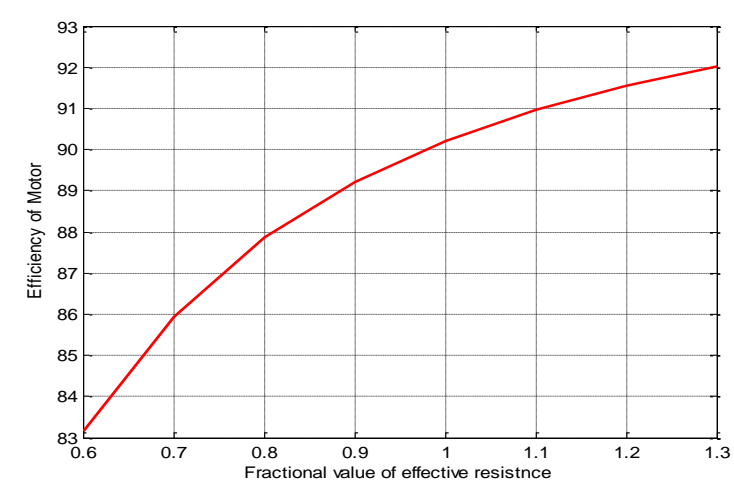

(a)

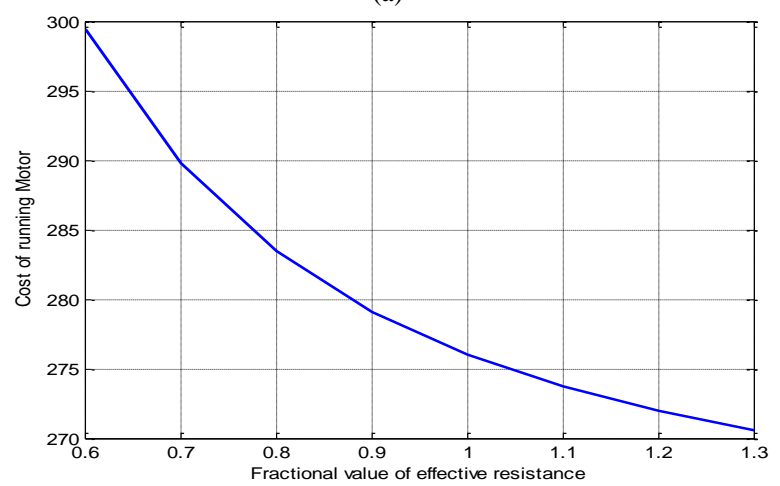

(b)

Fig. 6. Effect of varying the resulting combination of the armature and the series resistances for series motor

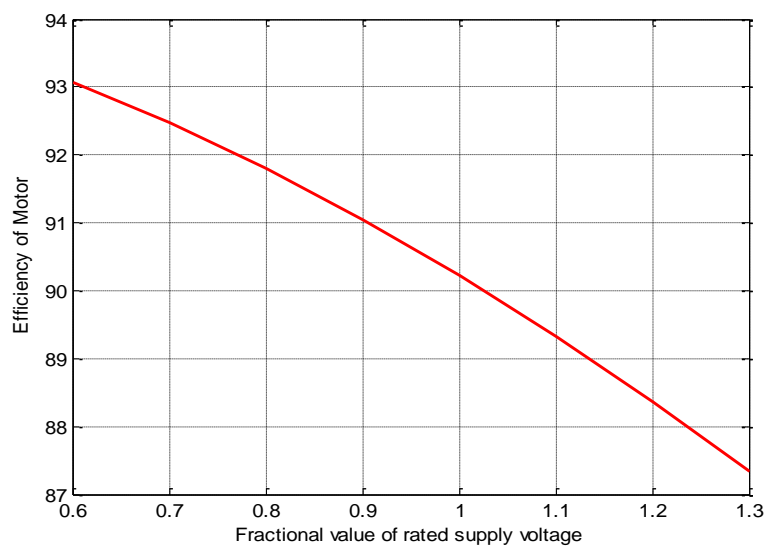

(a)

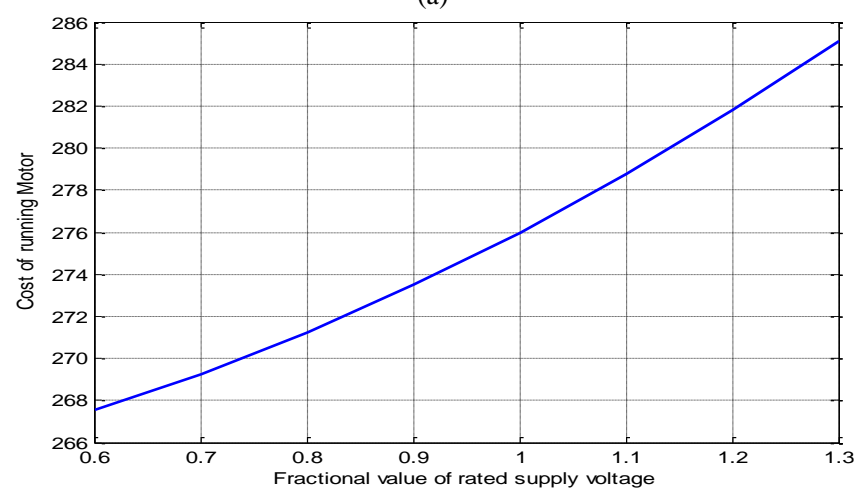

(b)

Fig. 7. Effect of varying the supply voltage for series motor

\section{DISCUSSION OF RESULT}

\section{A. Shunt Motors}

When controlling the motor's speed by varying the flux, an increase in the shunt field resistance decreases the shunt field current; decreases the flux in turn (since the flux is proportional to the shunt current) and eventually increases the speed.

At default (original value of flux), the efficiency is $80.40 \%$ with a running cost of $\$ 246.00$. Controlling (reducing) the motor's speed by increasing the flux, decreases the efficiency of the motor and increases the running cost of the motor below and above the default values of $80.4 \%$ and $\$ 246.00$ respectively. On the other side, increasing the motor's speed by reducing the flux increases the motor's efficiency and decreases the running cost. This is showed in Fig. 3 ( $\mathrm{a} \& \mathrm{~b}$ ).

Increasing the motor speed by reducing the armature resistance is found to increase the motor's efficiency and reduces its running cost. The reverse gives rise to reduced efficiency and increased running cost as seen in Fig. 4 (a \& b). Increasing the speed by increasing supply voltage reduces the motor's efficiency and increases cost of running the motor above the stipulated $80.40 \%$ and $\$ 246.00$ to as low and high as below as $75.31 \%$ and 262.73 respectively. Speed reduction using this method is best as efficiency and running cost are increased and reduced respectively. This is as shown in Fig. 5 (a \& b).

\section{B. Series Motors}

At default (original value of flux), the efficiency is $90.22 \%$ with a running cost of 276.00 . Increasing the motor's speed by decreasing the flux (or decreasing the armature resistance) increases the motor's running cost and decreases the efficiency above and below the default values respectively. On the other hand, decreasing the motor's speed by increasing the flux (or increasing the armature resistance) increases the motor's efficiency and decreases the running cost. This is shown in Fig. 6 ( $a \& b)$.

Increasing the motor speed by increasing the supply voltage beyond the rated value decreases the efficiency below its $90.22 \%$ default value and increases the running cost beyond its $\$ 276.00$ default value. On the other hand, decreasing the speed by decreasing the supply voltage below its rated value increases its efficiency above $90.22 \%$ and reduces the running cost below 276.00 .

With the results considered, the motor's speed controller can use the most appropriate method depending whether he is increasing or decreasing the speed of the motor; see Fig. 7 $(\mathrm{a} \& \mathrm{~b})$.

\section{CONCLUSION}

Since the desire is to either increase or decrease the speed of these dc motors above or below rated speed depending on the desired usage, we can now suggest which method should be adopted from the analysis. For increment above rated speed in shunt motors, the flux and armature control methods are recommended as it increases efficiency and reduces running cost. Speed reduction below rated values is best achieved using the voltage control as it increases efficiency and reduces running cost. For series motors, increase in the motor's speed above rated values reduces efficiency and increases running cost with all methods; reducing speed however favors all methods of speed control in these series motors as higher efficiency and lower running cost are experienced. 


\section{REFERENCES}

[1] B. L. Theraja and A. K.Theraja."A Textbook of Electrical Technology". S. Chand, 22nd Edition, Vol. 2, pp. 996 - 1078, 2005.

[2] S. Sharma, S. S. Oberoi andN. Siddharth."Speed Control Method of DC series motor'International Journal of Innovative Research in Technology (IJIRT) Vol. 1 Iss 6.ISSN : 2349-6002, pp 1450 - 1453. 2014.

[3] A. Dwivedi. "Speed Control of DC Shunt Motor with Field and Armature Rheostat Control Simultaneously" Advance in Electronic and Electric Engineering ISSN 2231-1297, Vol. 3, No. 1, pp. 77-80 C Research India Publications http://www.ripublication.com/aeee.htm. 2013.

[4] F. Loucif. "Dc motor speed control using PID controller", KINTEX, Gyeonggi-Do,

Korea. https://www.researchgate.net/publication/310416585, June 2005.

[5] J. C. Magsino and E. R. Magsino. "Speed and torque control of a dc shunt motor". https://www.researchgate.net/publication/272164467. 2015.

[6] A. U. Adoghe, S. O. Aliu, S. I. Popoola, and A. A. Atayero. "Digital Speed Control of DC Motor for Industrial Automation using Pulse Width Modulation Technique". Proceedings of the World Congress on Engineering Vol. I, WCE 2017, London, U.K. pp 2017

[7] R. Krisnan. "Electric Motor Drives: Modeling, Analysis, and Control". Prentice Hall, New York, pp 91 - 98. 2001.

[8] C. Krause, O. Wasynzuck, and S. Sudhoff. "Analysis of Electric Machinery and Drive Systems".Wiley Inter-Science, New York, pp $113-119.2002$

[9] R. Gupta, R. Lamba and S. Padhee. "Thyristor Based Speed Control Techniques of DC Motor: A Comparative Analysis" International Journal of Scientific and Research Publications, Volume 2, Issue 6, ISSN 2250-3153, pp 1 - 6, June 2012.

[10] S. S. Thakareamd and S. Kompelli. "Design and implementation of dc motor speed control based on pic microcontroller" International Journal of Engineering and Computer Science ISSN:2319-7242. Vol. 3, Issue9, pp 8075 - 8079, 2014.

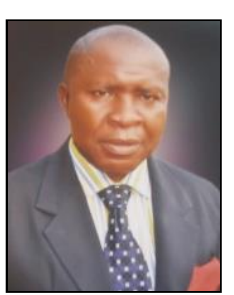

Engr. Dr. Obi, Patrick Ifeanyi, FNSE, MNIEEE is a Senior Lecturer in Electrical/Electronic Department, Michael Okpara University Umudike Abia State, Nigeria. $\mathrm{He}$ is a $\mathrm{PhD}$ holder in Electrical Power Systems/Machines from Chukwuemeka Odumegwu Ojukwu University, (COOU), Uli Anambra State (Fmr. ANSU). His research interest is in Power Systems and Control Devices.

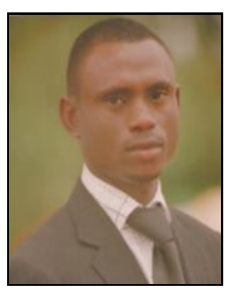

Osita Oputa obtained B.Eng and M.Eng degrees in Electrical/Electronic Engineering from the University of Port Harcourt, Nigeria in 2004 and 2010 respectively. $\mathrm{He}$ is currently a $\mathrm{PhD}$ student at the University of Nigeria Nsukka (UNN) and teaching in Micheal Okpara University of Agriculture Umudike, Abia state, Nigeria. His research interest is in Power system engineering/machines protection and optimization. He has published a number of academic journals in the past.

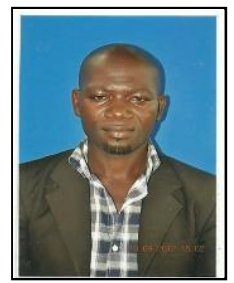

Engr. Okeke C. A., B.Eng, M.Eng, MNSE, holds a Bachelors Degree in Electrical/Electronic Engineering, Enugu State University of Science and Technology, Enugu, Nigeria in 1998. A Masters Degree in Electrical/Electronic Engineering, majoring in Electronics and Communication from the same University in 2006. He is a member of Nigerian Society of Engineers (NSE) and Council for the Regulation of Engineering in Nigeria (COREN). He is also a member of International Research and Development Institute (IRDI). Engr. Chukwuma Okeke is currently lecturing in Michael Okpara University of Agriculture, Umuduke, Abia State, Nigeria.

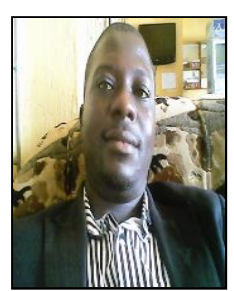

Gerald Chigozie Diyoe received his B.Eng and M.Eng from the Department of Electrical Engineering, University of Nigeria, Nsukka (UNN) in 2005 and 2013 respectively. He is currently a $\mathrm{Ph} . \mathrm{D}$ student in the same Department and a lecturer at the Department of Electrical and Electronic Engineering, Michael Okpara University of Agriculture Umudike, Abia State, Nigeria. His research interests are on Power Electronics, conventional and multilevel inverter, Induction motor drives.

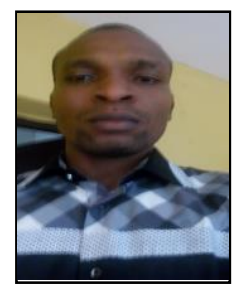

Mr Ifeanyichwukwu Kalu Onwuka Obtained B.Eng and M.Eng at Federal University of science and technology owerri and University of Nigeria Nsukka in 2006 and 2013 resppectively. He is currently on a Ph.D study in the University of Nigeria Nsukka. He worked with the Abia State Ministry of Science and Technology as an Engineer from 2008 till 2013. From 2013 till date, he Lectures in the Michael Okpara University of Agriculture UmudikeHis research interest is in Electric Machine Drives. 